\title{
Thrombin Stimulates the Adherence of Neutrophils to Human Endothelial Cells In Vitro
}

\author{
Guy A. Zimmerman, Thomas M. Mclntyre, and Stephen M. Prescott \\ Nora Eccles Harrison Cardiovascular Research and Training Institute and Department of Internal Medicine, \\ University of Utah School of Medicine, Salt Lake City, Utah 84112
}

\begin{abstract}
Highly purified human thrombin stimulates the adherence of polymorphonuclear leukocytes (PMNs) to vascular endothelial cells (EC). When Indium-labeled PMNs were incubated with primary monolayers of cultured human umbilical vein $\mathrm{EC}$, the basal adherence was $10 \pm 1 \%$ of the PMNs at $5 \mathrm{~min}$. Addition of thrombin $(2 \mathrm{U} / \mathrm{ml})$ increased the mean adherence to $42 \pm 15 \%$. Enhanced neutrophil adherence in response to thrombin was confirmed by experiments with unlabeled leukocytes, examined by phase contrast and scanning electron microscopy. The action of thrombin was on the EC, since it did not directly stimulate PMN adhesiveness when measured by aggregation or by adherence to nylon fiber columns. Furthermore, enhanced neutrophil adherence occurred when endothelial monolayers were treated with thrombin and washed before adding ${ }^{111}$ Indium ( ${ }^{111}$ In)-labeled PMNs. Thrombin that had been inactivated with antithrombin III and heparin did not enhance neutrophil adherence. Prothrombin, Factor $\mathrm{Xa}$, and fibrinogen were also ineffective. The stimulated adherence of PMNs was maximal 5 min after incubation of the EC with thrombin, and decreased thereafter. The response was dose-dependent, with half-maximal stimulation at 0.2-0.25 $\mathrm{U}$ thrombin/ml. The enhanced PMN adherence caused by thrombin may result in part from the production of platelet-activating factor (PAF) by the stimulated EC since (a) thrombin-stimulated EC synthesize PAF with a time course and concentration dependence that are similar to the time and concentration relationships for thrombin-stimulated PMN adherence, (b) PAF itself promoted neutrophil adherence to the EC monolayers, and (c) pretreatment of PMNs with PAF decreased the adherence stimulated by thrombin and PAF, but not adherence stimulated by $\boldsymbol{N}$-formylmethionyl-leucyl-phenylalanine and C5a fragments, which indicates specific desensitization of PAF-mediated adherence.

These studies demonstrate the endothelial cell-dependent stimulation of PMN adherence by thrombin, a novel mechanism of enhanced leukocyte adherence that may be important in interactions between the coagulation and inflammatory systems.
\end{abstract}

\section{Introduction}

Leukocytes, as well as erythrocytes and platelets, are found in thrombi and are active participants in experimental and clinical

Address correspondence and reprint requests to Dr. Zimmerman, Nora Eccles Harrison, CVRTI, Building 100, University of Utah, Salt Lake City, Utah 84112. 1985.

Received for publication 10 June 1985 and in revised form 13 August

J. Clin. Invest.

(C) The American Society for Clinical Investigation, Inc.

$0021-9738 / 85 / 12 / 2235 / 12 \$ 1.00$

Volume 76, December 1985, 2235-2246 thrombosis (1). Neutrophils (neutrophilic polymorphonuclear leukocytes, polymorphonuclear cells [PMNs], ${ }^{1}$ granulocytes) are frequently seen in thrombi (1), and in some circumstances are the predominant cells that accumulate in injured or inflamed vessels in humans (1-4). In addition, vascular thrombosis is a feature of pathologic tissue inflammation (5). Several mechanisms may link the coagulation and inflammatory systems. Generation of biologically active products by the plasma contact activation system, such as Factors XIIa and XIa, kallikrein, and bradykinin, may result in inflammation as well as thrombosis (6-8). Furthermore, products of this system may activate the complement cascade, which results in the generation of the chemotactic fragments C5a and C5a desarg $(5,6,9)$. Mediators released from platelets during coagulation or after contact with injured vascular intima, such as platelet-derived growth factor and platelet factor IV, have proinflammatory effects (10). Neutrophils also release substances that can activate coagulation and initiate fibrinolysis $(1,11)$, and cause platelet activation and the release of platelet products $(1,12,13)$.

In earlier studies $(14,15)$ we found that thrombin stimulated human endothelial cells to produce platelet-activating factor (PAF; 1-alkyl-2-acetyl-sn-glycero-3-phosphocholine), a biologically active phospholipid. The PAF synthesized by the endothelial monolayers remained associated with the cells, rather than being released (14). Production of PAF by endothelial cells (EC) in response to thrombin potentially represents a new mechanism linking the common pathway of the coagulation system (16) with the acute inflammatory process, since PAF is a potent stimulus for the activation of human neutrophils as well as platelets $(14,15,17,18)$. Preliminary results indicated that thrombin stimulated the adherence of neutrophils to cultured human endothelium (14), which suggests the possibility that endothelial cell-derived PAF may mediate interactions between leukocytes and the endothelial surface.

In this paper we report observations that further support this hypothesis. The experiments demonstrate that thrombin stimulates the adherence of neutrophils via a mechanism that requires the endothelial cells, that PAF is also an agonist for stimulated PMN adherence, and that the enhanced PMN adherence in response to thrombin may be in part mediated by the production of PAF by the endothelial cells.

\section{Methods}

Materials. Purified human thrombin and coagulation Factor Xa were provided by Dr. George J. Broze, Washington University, St. Louis, MO. The stock solution of thrombin contained $1,050 \mathrm{U} / \mathrm{ml}$ with a specific

1. Abbreviations used in this paper: EC, endothelial cells; fMLP, $N$-formylmethionyl-leucyl-phenylalanine; HBSS, Hanks balanced salt solution; HBSS/A, HBSS with $5 \mathrm{mg} / \mathrm{ml}$ human serum albumin; ${ }^{111}$ In, ${ }^{11}$ Indium; PAF, platelet-activating factor (1-alkyl-2-acetyl-sn-glycero-3-phosphocholine); PMNs, polymorphonuclear cells. 
activity of $2,920 \mathrm{U} / \mathrm{mg}$. It was diluted to $20 \mathrm{U} / \mathrm{ml}$ in Hanks balanced saline solution (HBSS) and stored in aliquots at $-20^{\circ} \mathrm{C}$ for use in the experiments to be described. Leukotriene $\mathrm{B}_{4}$ was a gift from Dr. Joshua Rokach (Merck-Frosst Canada, Inc., Quebec, Canada). PAF was purchased from Avanti Polar Lipids, Inc. (Birmingham, AL). $N$-formylmethionyl-leucyl-phenylalanine (fMLP), prothrombin, and fibrinogen were from Sigma Chemical Co. (St. Louis, MO) and human albumin was purchased as a $25 \%$ stock solution ("Albuminar 25") from Armour Pharmaceutical Co. (Tarrytown, NY). Medium 199, L-glutamine, antibiotic solutions, and HBSS were from M.A. Bioproducts (Walkersville, MD).

Human umbilical vein endothelial cell culture. Endothelial cells were isolated from umbilical veins and cultured in gelatin-treated $25-\mathrm{mm}$ wells in multiwell plates (Costar, Cambridge, MA), or 35-mm polystyrene petri dishes (Corning Glass Works, Corning, NY) using a minor modification of previously reported methods $(14,15,19)$. After being isolated from the vessels with collagenase, the EC were suspended in medium 199 with $20 \%$ pooled human serum, supplemental $L$-glutamine, and antibiotics (19). We prepared the serum by allowing blood from 3-6 normal donors to clot in sterile glass tubes; we then performed centrifugation of the serum twice at $3,000 \mathrm{~g}$ for $5 \mathrm{~min}$ at $4^{\circ} \mathrm{C}$, and once at $12,000 \mathrm{~g}$ for $15 \mathrm{~min}$ at $4^{\circ} \mathrm{C}$, and then sequential filtration through 0.2 $\mu \mathrm{m}$ filters before addition to the medium. The EC were incubated in $5 \%$ $\mathrm{CO}_{2}, 95 \%$ air for $4 \mathrm{~h}$; after this period the nonadherent cells were aspirated, the adherent cells were washed 1-3 times with HBSS, and new culture medium was added. The cells were returned to an atmosphere of $95 \%$ air, $5 \% \mathrm{CO}_{2}$ until confluent (5-7 d), with media changes every $72 \mathrm{~h}$. Only primary cultures that had been tightly confluent for $24 \mathrm{~h}$ or more (19) were used for these experiments.

Isolation and labeling of human neutrophils. Neutrophils were isolated from venous blood using dextran sedimentation and Ficoll-Hypaque gradients as described (20). A group of healthy subjects of various ages and both sexes served as PMN donors. The isolated PMNs (95-100\% PMNs) were suspended in HBSS with $5 \mathrm{mg} / \mathrm{ml}$ human serum albumin (HBSS/A) for ${ }^{111}$ Indium (" EC. We have previously shown that neutrophils isolated in this way do not contain functionally significant numbers of platelets (19). Furthermore, no adherent platelets were seen when neutrophil suspensions were incubated with EC monolayers and examined by scanning electron microscopy.

For labeling with ${ }^{11}$ Indium, 50 to $200 \times 10^{6} \mathrm{PMNs}$ were suspended in $5 \mathrm{ml}$ of HBSS/A. Indium oxine (Medi-Physics, Inc., Richmond, CA, or Amersham Corp., Arlington Heights, IL) was supplied by the Department of Radiopharmacy of the University of Utah and was added in a concentration of $0.2-0.5 \mu \mathrm{Ci} / 10^{6} \mathrm{PMNs}$, a dose that is well below the level that causes radiation damage to the leukocytes (21). The PMNs and Indium were incubated for $5-15 \mathrm{~min}$ at $37^{\circ} \mathrm{C}$ and the suspension was then centrifuged at $450 \mathrm{~g}$ for $5 \mathrm{~min}$ at room temperature. The supernate was saved and the pelleted PMNs were gently resuspended in $10 \mathrm{ml} \mathrm{HBSS} / \mathrm{A}$. This suspension was mixed and then centrifuged again at $450 \mathrm{~g}$ for $5 \mathrm{~min}$ at room temperature. The supernate was decanted, pooled with the supernate from the first centrifugation, and the radioactivity in the pooled supernates and the cell pellet was determined. Under these conditions $30-80 \%$ of the Indium was taken up by the PMNs. The labeled PMNs were resuspended in an appropriate volume of HBSS/A to yield a cell concentration of $5.5 \times 10^{6}$ neutrophils per $\mathrm{ml}$.

In some experiments PMNs were labeled with " II In-tropolonate (22) rather than ${ }^{111}$ In-oxine. " 1 In-chloride $\left(0.2-0.5 \mu \mathrm{Ci} / 10^{6} \mathrm{PMNs}\right)$ was mixed with $26 \mu \mathrm{g}$ of tropolone (Aldrich Chemical Co., Inc., Milwaukee, WI) in a volume of $0.5 \mathrm{ml}$ of $0.9 \% \mathrm{NaCl}$ before addition to the PMN suspension, or the two agents were added separately to the PMN suspension. The PMN suspension was then incubated for $15 \mathrm{~min}$ at $37^{\circ} \mathrm{C}$ and the remainder of the procedure was done as previously described.

After labeling with ${ }^{11}$ In-oxine or tropolonate, $98 \%$ or more of the neutrophils excluded Trypan Blue. Their functional status was similar to that of unlabeled PMNs since $(a)$ they spontaneously adhered to nylon fiber columns and the basal adherence could be increased by increasing the weight of nylon fiber, a functional assay of viability $(23),(b)$ adherence to the columns could be increased by incubating the labeled neutrophils with $\mathrm{fMLP}, \mathrm{LTB}_{4}$, or C5a desarg, which are known agonists of neutrophil adherence $(20,24,25),(c)$ the labeled neutrophils aggregated in response to $\mathrm{AMLP}, \mathrm{LTB}_{4}, \mathrm{C5a}$ desarg, and PAF in a concentration-dependent fashion (see Results; Fig. 4), and (d) the relative aggregation responses of Indium-labeled neutrophils to $\mathrm{AMLP}, \mathrm{LTB}_{4}$, and PAF reproduced the pattern that we have observed with unlabeled PMNs (Zimmerman, G. A., and D. Klein-Knoeckel, manuscript submitted for publication).

In an experiment to determine if ${ }^{111}$ In was released from stimulated PMNs, labeled neutrophil suspensions were incubated with buffer, PAF, or $\mathrm{AMLP}$ for $5 \mathrm{~min}$ at $37^{\circ} \mathrm{C}$, centrifuged, and the radioactivity in the pellets and supernates was counted. $5 \%$ of the counts were found in the supernate of buffer-treated PMNs, $4 \%$ in that of PAF-stimulated cells, and $5.8 \%$ of the counts were in the supernate from fMLP-stimulated PMNs. We confirmed that $\mathrm{MLP}$ and PAF activated the PMNs by measuring aggregation of the neutrophils in response to the agonists in parallel incubations. In a second experiment, "'In-labeled PMNs were incubated for 30 min with EC that had been treated with $1 \mathrm{U} / \mathrm{ml}$ thrombin (see next section and Results). The PMN suspensions were removed, centrifuged, and the radioactivity in the pellets and supernates were determined; 5.5 and $6 \%$ of the counts were found in the supernates of duplicate samples.

Adherence of labeled neutrophils to endothelial cell monolayers. Endothelial monolayers that had been tightly confluent (19) for a minimum of $24 \mathrm{~h}$ before use were washed with $\mathrm{HBSS}\left(37^{\circ} \mathrm{C}\right)$ after removal of the culture medium. Aliquots of labeled PMN suspension $(0.45 \mathrm{ml}$ if the monolayers were in $25-\mathrm{mm}$ wells and $0.9 \mathrm{ml}$ if they were in $35-\mathrm{mm}$ dishes) were layered over the EC; then control buffer or buffer containing an agonist (thrombin, PAF, fMLP, etc.) was added, and the PMNs and $E C$ were incubated for various times as indicated in an atmosphere of $5 \% \mathrm{CO}_{2}, 95 \%$ air at $37^{\circ} \mathrm{C}$. When the volume of PMNs was $0.45 \mathrm{ml}$, the agonist or control solutions were added in $0.05-\mathrm{ml}$ volumes and the solutions were added in $0.1-\mathrm{ml}$ volumes when the PMN volume was 0.9 $\mathrm{ml}$. In the figures in Results, the concentrations of agonists indicate their final concentration in the incubation mixture.

In some experiments control solutions, or solutions containing thrombin or other agents, were added to EC monolayers, incubated for various periods, and removed. The monolayers were then washed again, "III-PMNs were added and incubated for $5 \mathrm{~min}$, and adherence was determined (Results, Figs. 3 and 5).

After incubation of "IIIn-labeled PMNs with EC, the PMN suspensions were carefully aspirated from the monolayers (Fraction A) and counted in a radiation counter (Gamma 5000; Beckman Instruments, Inc., Fullerton, CA). The monolayers were then washed twice with HBSS $(0.5 \mathrm{ml}$ for $25-\mathrm{mm}$ monolayers and $1.0 \mathrm{ml}$ for $35-\mathrm{mm}$ monolayers $)$ and the washings from each monolayer were individually pooled (Fraction B) and counted. After this step the dishes were routinely inspected by phase contrast microscopy to document that PMNs were adherent and that the EC monolayers were intact. The monolayers then were treated with $1 \mathrm{M} \mathrm{NH}_{4} \mathrm{OH}$ for a minimum of $1 \mathrm{~h}$ at room temperature to dissolve the EC and adherent PMNs. The culture vessels were scraped with a cotton-tipped applicator and the $\mathrm{NH}_{4} \mathrm{OH}$ was aspirated; a second volume of $\mathrm{NH}_{4} \mathrm{OH}$ was added and the plates were scraped again. The $\mathrm{NH}_{4} \mathrm{OH}$ washings and the cotton-tipped applicators from each monolayer were pooled and this fraction (Fraction C), containing the "11'In from neutrophils adherent to the endothelial cells, was also counted. The total radioactivity recovered was calculated by adding the radioactivity (counts per minute) present in Fractions A, B, and C. Routinely, 95-100\% of the radioactivity was recovered. The percentage of PMNs adherent to the EC monolayers was calculated by dividing the radioactivity in Fraction $\mathrm{C}$ by the total radioactivity recovered (Fractions $\mathrm{A}+\mathrm{B}+\mathrm{C}$ ). The results were qualitatively unchanged if they were expressed as the absolute amount of radioactivity associated with the EC monolayers (Fraction C). Basal and stimulated adherence was measured in duplicate or triplicate in some experiments; the variation between monolayers was $<5 \%$ within each study.

Adherence of Indium-labeled PMNs to nylon fiber columns. A modification of a previously reported method (20) was used. Columns con- 
taining nylon fiber were made as described and warmed to $37^{\circ} \mathrm{C}$. Aliquots of "11 In-labeled PMNs $(0.9 \mathrm{ml})$ were mixed with control or agonist solution $(0.1 \mathrm{ml})$ for $30 \mathrm{~s}$ to $5 \mathrm{~min}$ at $37^{\circ} \mathrm{C}$ on a mixing platform; $1.0-\mathrm{ml}$ volumes were then added to duplicate or triplicate columns and allowed to drain by gravity at $37^{\circ} \mathrm{C}$ over a 15 -min period. The radioactivity in the effluents and the columns were counted separately and the percentage of neutrophils adherent to the nylon fiber was calculated as the radioactivity (counts per minute) associated with the column divided by the sum of the counts associated with the column and in the effluent.

Neutrophil aggregation. The aggregation of ${ }^{11}$ In-labeled and unlabeled neutrophils in response to thrombin, or agonists known to activate PMNs, was measured by a modification (Zimmerman, G. A., and D. Klein-Knoeckel, manuscript submitted for publication) of a previously described technique (14). Briefly, $0.45 \mathrm{ml}$ of granulocyte suspension was stirred $(900 \mathrm{rpm})$ at $37^{\circ} \mathrm{C}$ in a siliconized cuvette in a dual channel aggregometer (model 300BD; Payton Scientific, Inc., Buffalo, NY) for $2 \mathrm{~min} .50 \mu \mathrm{l}$ of an agonist solution (control buffer, thrombin, or agents such as $\mathrm{MLP}$ ) were then added and the resultant aggregation wave was recorded over a 1-3-min period. The aggregation waves were quantitated as the increase in light transmission (14) at $1 \mathrm{~min}$ after addition of the agonist, since we have previously shown that the aggregation responses are maximal at this interval under the conditions of these experiments (Zimmerman, G. A., and D. Klein-Knoeckel, manuscript submitted for publication).

Desensitization studies. In experiments to determine if neutrophils become specifically desensitized $(26,27)$ to subsequent stimulated adherence, we treated suspensions of control or "'In-labeled PMNs with buffer or PAF and then studied their adherence and aggregation responses to agonists of different classes. In preliminary experiments using PMN aggregation, we found that neutrophils treated with PAF for 5 min at $37^{\circ} \mathrm{C}$ became hyporesponsive to subsequent stimulation with PAF. The response to subsequent stimulation with MLP varied, depending on the concentration of PAF used in the pretreatment period. When neutrophils were pretreated with low concentrations of PAF $\left(10^{-9}\right.$ or $\left.10^{-8} \mathrm{M}\right)$, the response to a second stimulation with PAF was inhibited, whereas the response to $\mathrm{AMLP}$ was maintained; this confirms selective desensitization of the PMNs (27). When higher concentrations of PAF $\left(10^{-7}\right.$ or $\left.10^{-6} \mathrm{M}\right)$ were used for pretreatment, the leukocytes became hyporesponsive to both PAF and AMLP ("nonspecific desensitization") (26). The concentration of PAF that specifically desensitized neutrophils varied from neutrophil donor to neutrophil donor; therefore, we screened donors and chose those whose PMNs demonstrated specific desensitization with PAF at a concentration of $10^{-8} \mathrm{M}$. ${ }^{111}$ In-labeled PMNs from these subjects were treated with $10^{-8} \mathrm{M}$ PAF or control buffer for $5 \mathrm{~min}$ at $37^{\circ} \mathrm{C}$ on a mixing platform. Aliquots of the PMNs $(0.9 \mathrm{ml})$ were transferred to EC monolayers, $0.1 \mathrm{ml}$ of a second agonist was added, the neutrophils and EC were incubated together for $5 \mathrm{~min}$, and the adherence of PMNs to the EC was determined. Evidence for specific desensitization of the neutrophils by PAF in these studies was confirmed by parallel aggregation assays.

Data comparisons. All results are indicated as the mean \pm 1 standard deviation. Where indicated, means were compared using a paired student's $t$ test.

\section{Results}

Thrombin stimulates the adherence of neutrophils to endothelial cell monolayers. When thrombin was added to suspensions of ${ }^{111}$ In-labeled PMNs overlying EC monolayers, adherence of the leukocytes to the endothelial cells was markedly stimulated. In nine experiments in which EC monolayers and neutrophils were incubated with thrombin for $5 \mathrm{~min}, 42 \pm 15 \%$ of the neutrophils adhered compared with $10 \pm 1 \%$ of the PMNs in dishes incubated with control buffer $(P=0.0001)$. The stimulated adherence in response to thrombin was dependent on the concentration of thrombin (Fig. 1). Half-maximal stimulation of neutrophil ad-

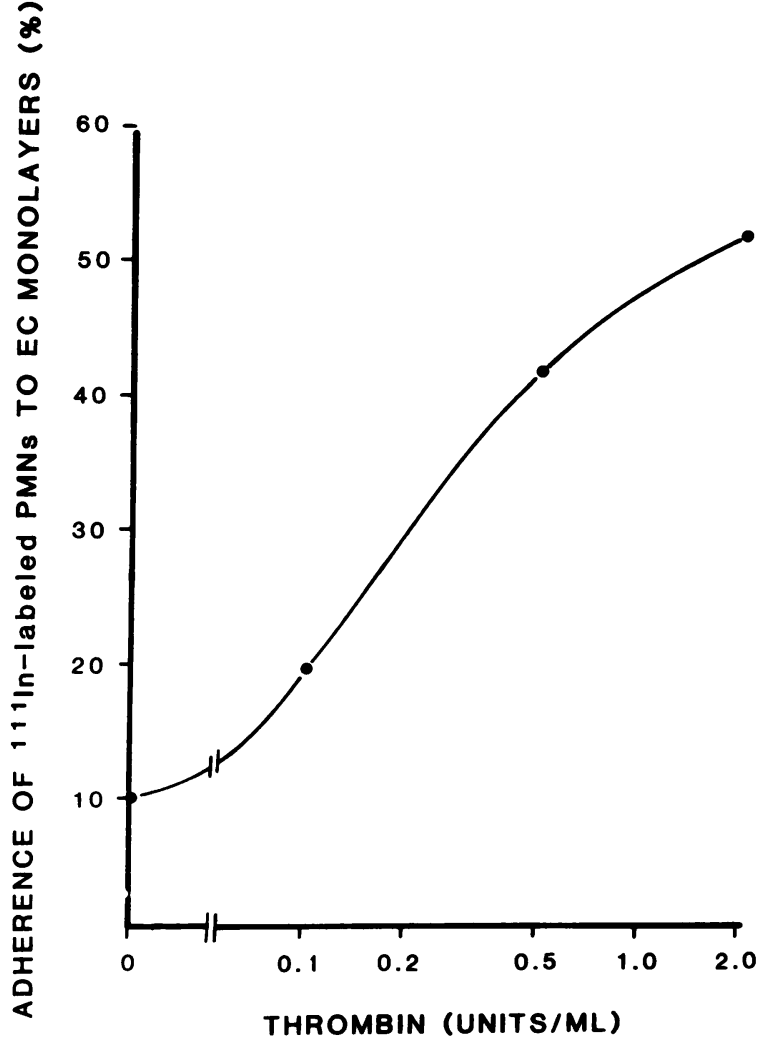

Figure 1. The stimulated adherence of Indium-labeled neutrophils to endothelial cells is dependent on the concentration of thrombin. Human thrombin was added to suspensions of ${ }^{111}$ In-labeled PMNs overlying EC monolayers and incubated for $5 \mathrm{~min}$ at $37^{\circ} \mathrm{C}$, after which the percentage of labeled neutrophils adherent to the monolayers was determined (see Methods). The figure illustrates the data from one experiment. The results were similar in a second experiment with endothelial cells from a different isolate.

herence occurred at a thrombin concentration of $0.2 \mathrm{U} / \mathrm{ml}$ and was maximal at $2 \mathrm{U} / \mathrm{ml}$. Two experiments showed that thrombin-stimulated adherence increased rapidly over the first 5-10 min of incubation, and then declined (not shown). We found that a commercially available thrombin preparation (Sigma Chemical Co.) also stimulated the adherence of ${ }^{111}$ In-labeled neutrophils to endothelial monolayers.

Phase contrast microscopy indicated that the adherence values calculated from the radioactivity associated with the EC monolayers correlated well with the adherence of intact neutrophils. We also found that thrombin stimulated the adherence of unlabeled neutrophils, as well as Indium-labeled PMNs (Fig. 2). This observation indicated that the increased adherence in response to thrombin was not due to an alteration in the neutrophils caused by the labeling procedure. As shown in Fig. $2 C$, scanning electron microscopy confirmed that thrombin caused PMNs to adhere to the surface of the endothelial monolayer. The neutrophils were adherent to the endothelial cell plasma membrane, but were only rarely seen to adhere to one another, which suggests that a factor associated with the endothelial cells mediated the interaction. Some of the neutrophils demonstrated polarization (24), which suggests that they had been activated in the process (Fig. $2 \mathrm{D}$ ).

In an experiment to determine if cyclooxygenase products synthesized by the EC influence thrombin-stimulated neutrophil 

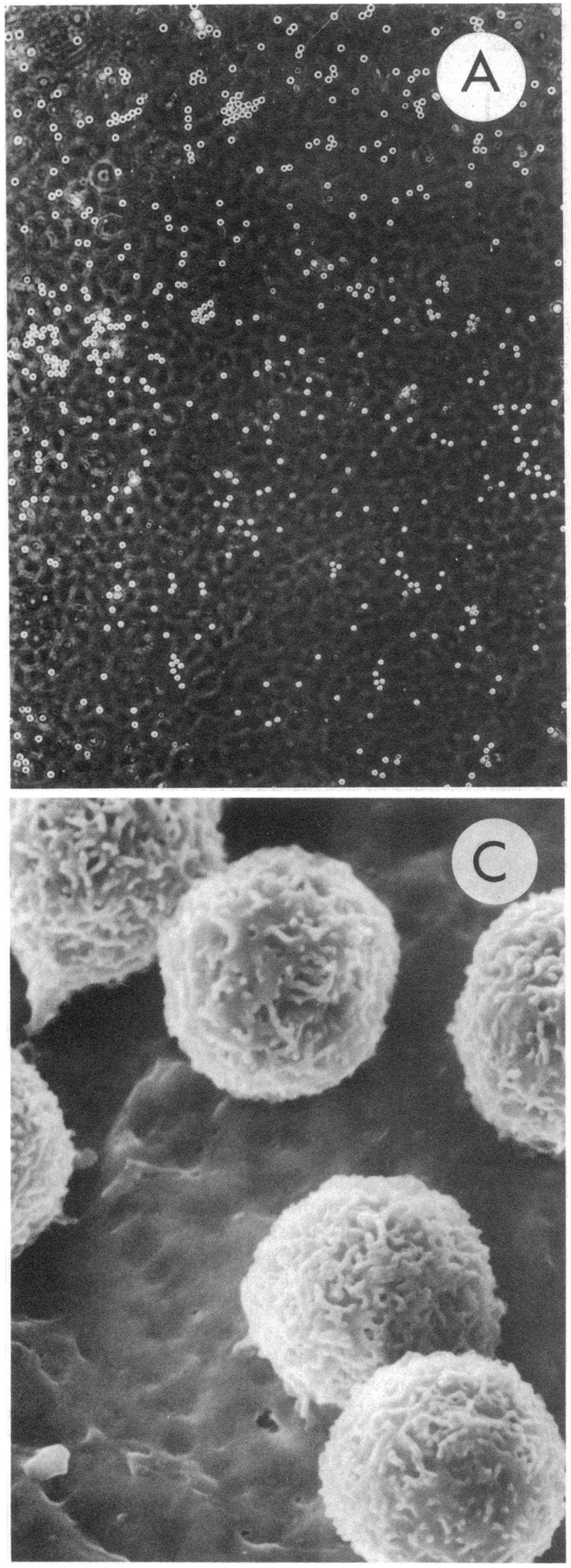

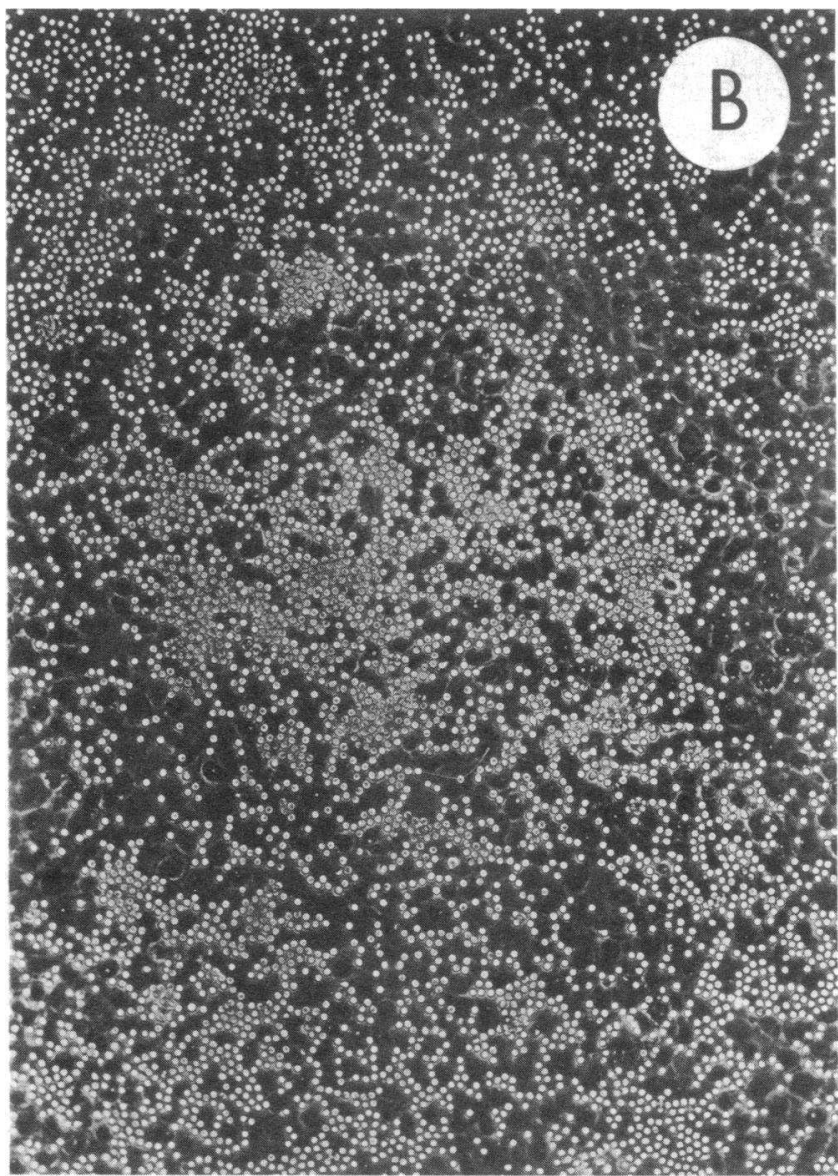

Figure 2. Thrombin stimulates the adherence of unlabeled neutrophils to endothelial monolayers. Suspensions of unlabeled neutrophils were incubated with EC monolayers for $5 \mathrm{~min}$ after treatment with control buffer or $2 \mathrm{U} / \mathrm{ml}$ thrombin. The PMN suspensions were then aspirated, the monolayers were washed twice with $1.0 \mathrm{ml}$ volumes of HBSS, and representative areas were photographed through a Nikon Diaphot-TMD inverted phase contrast microscope (magnification $X$ 250). There was a marked increase in the adherence of neutrophils in the thrombin-stimulated dish $(B)$ compared to the adherence in the dish treated with control buffer $(A)$. We found similar results in experiments with "'In-labeled PMNs (not shown). After examination by phase-contrast microscopy the monolayers were fixed with Karnovsky's solution, coated with atomic gold by vacuum evaporation, and examined with a Jeol-JSM35 scanning electron microscope. There were many neutrophils adherent to the thrombin-treated endothelial cells $(C$; magnification $\times 5,700)$. Some demonstrated polarization, with the development of lamellopodia and uropods $(D$, next page; magnification $\times 7,000$ ). No adherent platelets were seen. In an experiment using EC monolayers from the same isolate and "In-labeled PMNs from the same neutrophil donor that were used in the incubations shown in this figure, thrombin $(2.0 \mathrm{U} / \mathrm{ml})$ caused $27 \%$ of the PMNs to adhere compared with $8 \%$ adherence in response to buffer. 


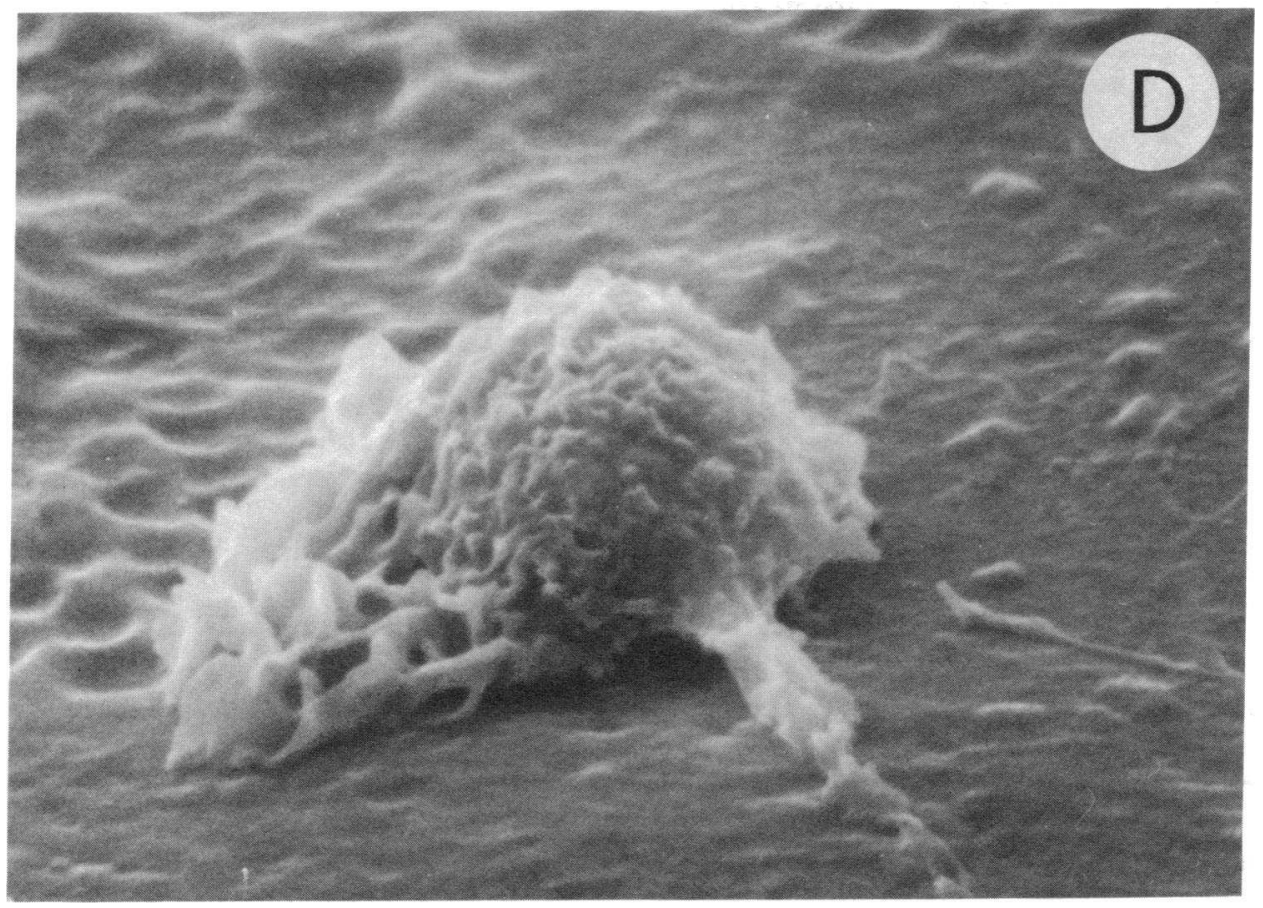

Figure 2 (Continued)

adherence (19), we pretreated the EC monolayers with control buffer or indomethacin for $30 \mathrm{~min}$ before incubating them with PMNs and thrombin. After a 5-min incubation, neutrophil adherence to indomethacin-treated EC monolayers stimulated by thrombin $(2 \mathrm{U} / \mathrm{ml})$ was sixfold greater than control, whereas the thrombin-stimulated adherence to buffer-treated monolayers was threefold greater than control. Additional experiments demonstrated that treatment of the endothelial cells with indomethacin under these conditions inhibited the production of prostacyclin by $>90 \%$, as measured by radioimmunoassay of 6-keto prostaglandin $\mathrm{F}_{1 \alpha}$.

Increased adherence of neutrophils is due to an effect of thrombin on the endothelial cells. The increased adherence that we observed could have been due to an effect of thrombin on the endothelial cells, on the neutrophils, or on both. To examine these possibilities, we tested the effect of thrombin when added to endothelial cells before incubation with neutrophils, and when it was added to neutrophils alone. We found that pretreatment of endothelial monolayers with thrombin before the addition of neutrophils resulted in stimulated adherence that was similar to that seen when it was added to PMN suspensions overlying the endothelial cells. Thus, when thrombin $(2 \mathrm{U} / \mathrm{ml})$ was incubated with EC for 5 min followed by washing with buffer to remove unbound thrombin (28), and PMN suspensions were added and incubated for $5 \mathrm{~min}$, the mean adherence to thrombin-treated EC was $49 \pm 14 \%$ compared to $8 \pm 2 \%$ to monolayers treated with control buffer $(n=3)$. The time course and concentration-response curves for thrombin-stimulated neutrophil adherence under these conditions are shown in Fig. 3, and are similar to results of experiments in which thrombin was added to PMNs overlying the endothelial monolayers. An experiment in which we incubated thrombin with EC for 2 min, removed the thrombin, and then added labeled neutrophils and incubated for various time periods (1-30 $\mathrm{min}$ ) yielded a time course similar to that shown in Fig. 3. This suggests that the stimulated adherence results from a rapid, endothelial cell-dependent process. Thrombin-treated endothelial cells did not contract under the conditions of these experiments (15).

To exclude the possibility that thrombin also directly stimulated the adhesiveness of neutrophils, we examined its effect on PMN aggregation $(14,26)$ and adherence to inert material (29). Thrombin did not stimulate the adherence of PMNs to nylon fiber columns (Table I), although fMLP, PAF, and $\mathrm{LTB}_{4}$ each stimulated adherence. We also found that thrombin did not cause ${ }^{111}$ In-labeled neutrophils to aggregate, another measure of adhesiveness. In the experiment shown in Fig. $4 A$, thrombin did not promote aggregation even though it stimulated neutrophils from the same suspension to adhere to endothelial monolayers (35\% adherence, compared with $9 \%$ in response to buffer). Furthermore, the neutrophils aggregated in response to PAF and fMLP, mediators that are known to directly stimulate the aggregation of PMNs $(27,30)$. In nine similar experiments (using ${ }^{111}$ In-labeled neutrophils as well as unlabeled PMNs) the maximal change in light transmission in response to thrombin was not different from the response to buffer alone $(0.44 \pm 0.07$ cm vs. $0.40 \pm 0.05 \mathrm{~cm}$ ), whereas the PMNs responded with typical aggregation waves to various concentrations of PAF and AMLP. Additional studies demonstrated that PAF, fMLP, and $\mathrm{LTB}_{4}$ stimulated aggregation of Indium-labeled PMNs with concentration-response relationships similar to those we have reported for unlabeled PMNs (Zimmerman, G. A., and D. KleinKnoeckel, manuscript submitted for publication), but that thrombin did not stimulate aggregation (Fig. $4 \mathrm{~B}$ ). In a separate experiment, thrombin caused a concentration-related increase in neutrophil adherence to EC (shown in Fig. 1) and stimulated platelets from the same donor to aggregate in a concentrationdependent fashion (not shown), but the same solutions of thrombin caused no aggregation of the subject's neutrophils at 


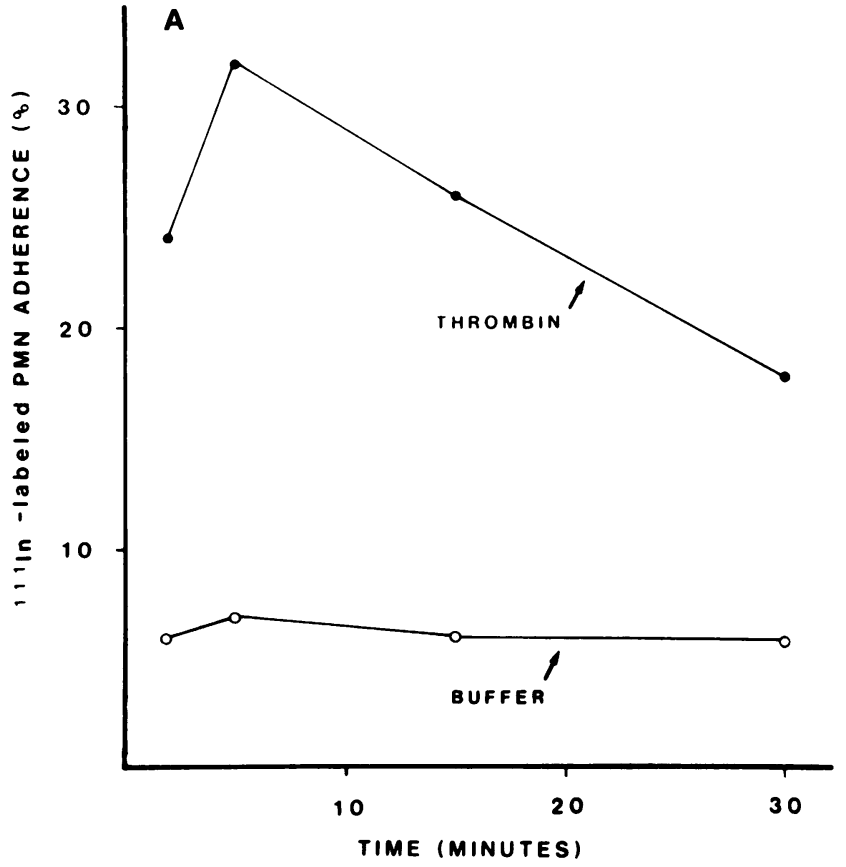

Figure $3(A)$. Time course of thrombin-stimulated neutrophil adherence. Endothelial monolayers were incubated with buffer (HBSS/A) or with buffer containing thrombin ( 1 or $2 \mathrm{U} / \mathrm{ml}$ ) for various times indicated on the horizontal axis. The thrombin solution was removed, the EC were washed with HBSS, and "III-PMNs were added and incubated for $5 \mathrm{~min}$. The adherence of labeled PMNs was then determined (Methods). The mean data from two experiments using EC from different cultures and PMNs from different donors are shown. In a third experiment the time course of thrombin-stimulated adherence was similar to that illustrated in the figure; neutrophil adherence to throm-

any of the concentrations tested. These experiments demonstrated that thrombin did not influence the PMN-endothelial cell interaction by directly increasing the adhesiveness of the neutrophils.

To determine if thrombin-stimulated endothelial cells released the factor that caused enhanced neutrophil adherence into the overlying medium, we incubated thrombin $(2 \mathrm{U} / \mathrm{ml})$ in

Table I. Effect of Thrombin on Neutrophil Adherence to Nylon Fiber Columns

\begin{tabular}{lll}
\hline Agonist & Percent adherence & No. \\
\hline Buffer & $60 \pm 2$ & 3 \\
Thrombin $(2 \mathrm{U} / \mathrm{ml})$ & $60 \pm 3$ & 3 \\
fMLP $\left(10^{-7} \mathrm{M}\right)$ & 90 & 1 \\
$\operatorname{LTB}_{4}\left(10^{-7} \mathrm{M}\right)$ & $86 \pm 5$ & 2 \\
PAF $\left(10^{-7} \mathrm{M}\right)$ & $87 \pm 1$ & 3 \\
\hline
\end{tabular}

${ }^{111}$ In-labeled neutrophils were incubated at $37^{\circ} \mathrm{C}$ for 2 or $5 \mathrm{~min}$ with buffer, PAF, IMLP, $\mathrm{LTB}_{4}$, or thrombin, added to $80 \mathrm{mg}$ nylon fiber columns, and the adherence was measured as described in Methods. The data indicate the results (mean $\pm 1 \mathrm{SD}$ ) of three experiments, each with PMNs from different donors. In an additional experiment (not shown) using nylon fiber columns weighing $50 \mathrm{mg}$ so that the basal, unstimulated neutrophil adherence was reduced $(20,23)$, thrombin did not enhance neutrophil adherence whereas PAF, $\mathrm{LTB}_{4}$, and fMLP each augmented the response.

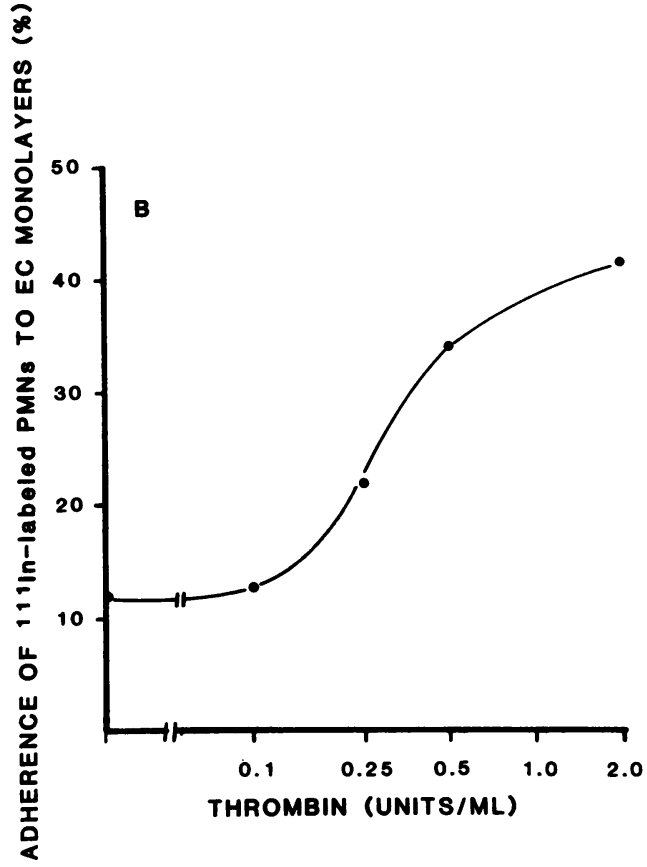

bin-treated EC returned to the basal level by $60 \mathrm{~min}$ (not shown). (B) Concentration-response curve for thrombin-stimulated neutrophil adherence. In three experiments, thrombin in various concentrations was incubated with EC monolayers for 2 or $5 \mathrm{~min}$, the thrombin solution was removed and the monolayers were washed with buffer, and ${ }^{111}$ InPMNs were added and their adherence determined after a 5-min incubation. Each point indicates the mean data from 2 or 3 experiments except the point at $0.25 \mathrm{U} / \mathrm{ml}$ thrombin, which was tested in one study.
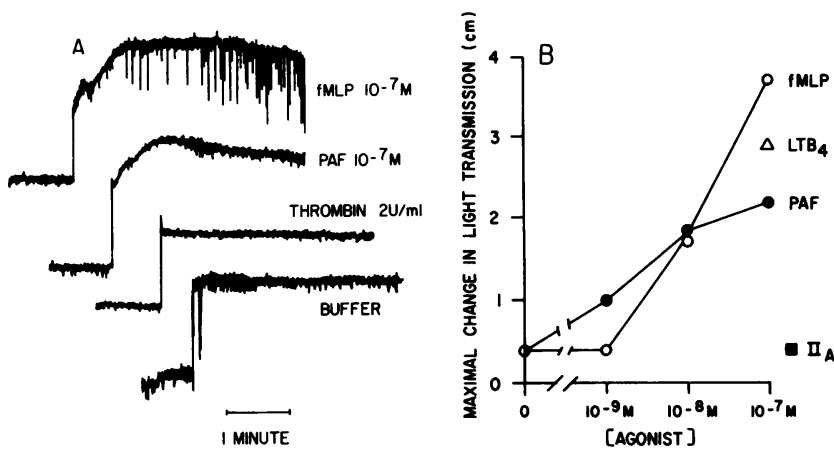

Figure 4. Thrombin does not directly stimulate neutrophil aggregation. (A) Aggregation curves traced directly from the record of an individual experiment are shown. Indium-labeled neutrophils, suspended in HBSS/A, were stimulated with buffer, thrombin (Ila; $2 \mathrm{U} / \mathrm{ml}$ ), PAF $\left(10^{-7} \mathrm{M}\right)$, or $\mathrm{fMLP}\left(10^{-7} \mathrm{M}\right)$ and the increase in light transmission, indicating aggregation of the leukocytes, was recorded (Methods). Thrombin did not stimulate neutrophil aggregation, although the cells aggregated in response to PMLP and PAF. The adherence of neutrophils from the same suspension to EC was increased fourfold (35\% vs. $9 \%)$ by thrombin $(2 \mathrm{U} / \mathrm{ml}) .(B){ }^{111} \mathrm{In}-\mathrm{PMNs}$ were suspended in HBSS/ A, stimulated with PAF, fMLP, $\mathrm{LTB}_{4}$, or thrombin ("IIa"; $2 \mathrm{U} / \mathrm{ml}$ ), and the maximal change in light transmission was measured $(A$ and Methods). The responses to PAF, fMLP, and $\mathrm{LTB}_{4}$ were similar to those in multiple experiments with unlabeled PMNs (not shown). Thrombin did not stimulate aggregation. A second experiment with "I'In-labeled PMNs demonstrated the same concentration-dependent aggregation to the neutrophil agonists (PAF, IMLP, LTB $_{4}$ ) but no aggregation response to thrombin (not shown). 
HBSS/A with endothelial monolayers for $5 \mathrm{~min}$ and added aliquots of this solution to neutrophil suspensions. No aggregation of the PMNs was observed, although they aggregated as expected when stimulated with PAF or fMLP. In an additional experiment, EC monolayers were incubated with control buffer or buffer containing thrombin $(2 \mathrm{U} / \mathrm{ml})$ for $5 \mathrm{~min}$ at $37^{\circ} \mathrm{C}$, washed, and $1 \mathrm{ml}$ of new HBSS/A was added to each. At the end of a 5 min incubation the HBSS/A solutions were removed, PMNs were suspended in them, and their adherence to nylon fiber columns was tested. The adherence of PMNs in HBSS/A incubated with thrombin-treated EC was the same as that of neutrophils suspended in buffer from control EC. In parallel incubations the adherence of neutrophils to thrombin-treated endothelial monolayers was almost sevenfold greater than to control monolayers ( $62 \%$ vs. $9 \%$ ). These findings indicate that the factor that promotes neutrophil adherence remains associated with thrombin-stimulated endothelial cells.

Stimulated neutrophil adherence requires active thrombin. The results of an experiment examining the effects of thrombin preparations and other coagulation factors on neutrophil adherence to endothelial cells are illustrated in Fig. 5. Thrombin that had been inactivated with antithrombin III did not stimulate neutrophil adherence to EC monolayers. Furthermore, prothrombin, coagulation Factor $\mathrm{Xa}$, and fibrinogen did not stimulate adherence, which demonstrated specificity of thrombin as an agonist for enhanced neutrophil adhesiveness to endothelial cells. A second experiment, using EC from a different culture, confirmed the findings in Fig. 5 and demonstrated that inactivation of thrombin with phenylmethylsulfonyl fluoride $(1 \mathrm{mM}$ or $10 \mathrm{mM}$, as described in reference 14 ) completely inhibited its ability to stimulate PMN adherence (not shown).

$P A F$ stimulates neutrophil adherence to EC monolayers. The time course and concentration-response relationships for thrombin-stimulated PAF production that we previously reported (14) are very similar to those for thrombin-stimulated neutrophil adherence (Figs. 1 and 3). These observations suggested that the augmented neutrophil adherence in response to thrombin was related to the endothelial cell production of PAF. The effect of PAF on neutrophil adhesion to human endothelial cells has not been characterized, although studies with experimental animals indicate that PAF may enhance neutrophil adhesiveness to endothelium in vivo $(32,33)$. We found that PAF stimulated PMN adherence to EC monolayers in a time-related and concentration-related fashion (Fig. 6), which demonstrated that this phospholipid can mediate the adhesive interaction between neutrophils and endothelial cells. In 19 experiments in which PAF $\left(10^{-7} \mathrm{M}\right)$ was added to suspensions of neutrophils overlying EC monolayers and the incubation continued for 5 min, the adherence was $23 \pm 6.5 \%$ compared with $9 \pm 2.5 \%$ for neutrophils treated with control buffer (range, 160 to $580 \%$ of control).

The results of these experiments were confirmed by phase contrast microscopy with both unlabeled and Indium-labeled PMNs (not shown). Scanning electron microscopy studies also showed that PAF caused neutrophils to adhere to endothelial monolayers. Polarized neutrophils (24), as well as spherical cells, were adherent to the endothelial cell plasma membranes (Fig. 7).

Pretreatment of PMNs with PAF specifically desensitizes their adherence to thrombin-stimulated endothelial cells. We postulated that the increased adherence of neutrophils to thrombintreated monolayers was mediated by PAF that was synthesized

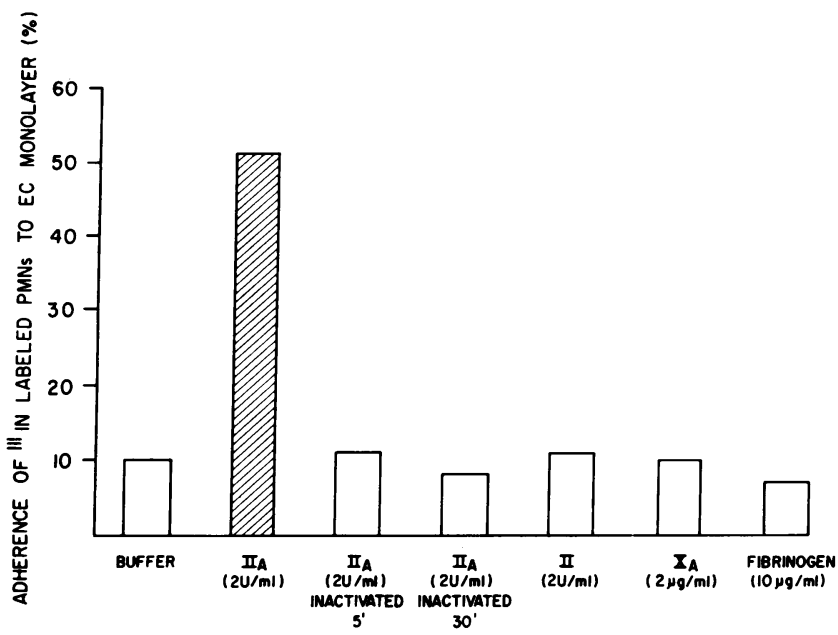

Figure 5. Neutrophil adherence requires active thrombin and is not stimulated by related coagulation factors. Endothelial monolayers were incubated for $5 \mathrm{~min}$ with buffer, thrombin (IIa), inactivated thrombin, coagulation Factors II (prothrombin) or Xa, or fibrinogen. They were then washed with buffer, incubated with "'In-PMNs for 5 min, and the adherence was determined. Thrombin was inactivated by incubation with an eightfold molar excess of antithrombin III and heparin $(2.0 \mathrm{U} / \mathrm{ml})$ for $5 \mathrm{~min}$ or $30 \mathrm{~min}$ at room temperature (14).

and associated with the endothelial cells $(14,15)$. To test this possibility, we studied the effect of pretreating neutrophils with PAF on their adherence to EC in response to thrombin, and compared the results to the response of PAF-treated neutrophils to other agonists. We reasoned that neutrophils pretreated with PAF should be less responsive to subsequent exposure to PAF, and thereby to become specifically hyporesponsive (27) to agonists that act by stimulating the EC to endogenously produce this phospholipid.

Fig. 8 demonstrates that pretreatment of PMNs with $10^{-8}$ M PAF markedly reduced their adherence in response to a second stimulation with PAF (in a concentration that would be expected to cause maximal adherence; Fig. $6 \mathrm{~B}$ ). In each of four experiments, pretreatment of neutrophils with PAF also caused significant inhibition of thrombin-stimulated adherence to endothelial monolayers. The adherence of PAF-desensitized neutrophils to thrombin-stimulated monolayers was reduced to a mean of $49 \%$ of the response of buffer-treated PMNs. In contrast, adherence stimulated by fMLP and C5a desarg (in zymosan-activated plasma) was not decreased, but instead was slightly enhanced. We have previously shown that fMLP and activated plasma do not stimulate PAF production by endothelial cells (15).

In one experiment, in which the EC were submaximally stimulated $(0.25 \mathrm{U} / \mathrm{ml}$ thrombin), neutrophil adherence was completely inhibited by prior desensitization with $10^{-8} \mathrm{M}$ PAF. In an additional experiment, pretreatment of PMNs with a higher concentration of PAF $\left(10^{-7} \mathrm{M}\right)$ completely inhibited neutrophil adherence to endothelial cells that had been stimulated with 2 $\mathrm{U} / \mathrm{ml}$ thrombin (i.e., thrombin-stimulated adherence was similar to that in response to buffer). However, adherence in response to $\mathrm{ALP}$ was not significantly decreased (Fig. $8 \mathrm{~B}$ ).

\section{Discussion}

Thrombin, a serine coagulation protease (16), interacts directly with human endothelium. Thrombin binds rapidly to cultured 


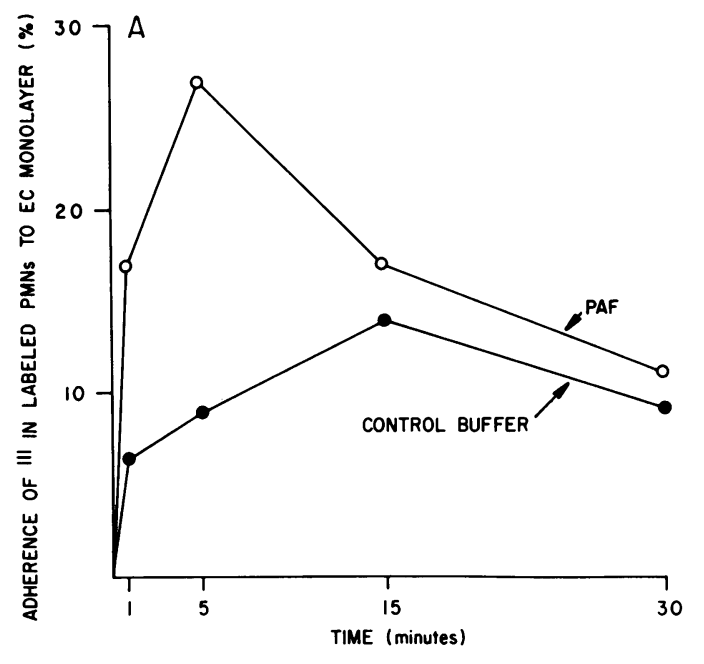

Figure 6. PAF stimulates Indium-labeled neutrophils to adhere to human endothelial cells. $(A)$ Time course. PAF $\left(10^{-7} \mathrm{M}\right)$ or control buffer was added to ${ }^{11}$ In-labeled PMN suspension overlying EC monolayers, or was incubated with PMNs for $30 \mathrm{~s}$ at $37^{\circ} \mathrm{C}$ before aliquots of the suspensions were added to EC monolayers. The incubations were continued for the indicated times and adherence of the neutrophils was determined (Methods). The figure indicates the results of five experiments. The standard deviation at each point was $5 \%$ or

umbilical vein EC (28), and causes a variety of biochemical and biologic effects $(14,15,33-42)$. In this report we show that thrombin, in concentrations similar to those that have been measured in clotting whole human blood (43), stimulates the adherence of neutrophils to human endothelial monolayers (Figs. $1-3,5)$. The enhanced neutrophil adherence is dependent on the endothelial cells and may result in part from the synthesis of PAF by them.

We found that neutrophil adherence in response to thrombin required the presence of endothelial cells. Thrombin did not stimulate the adherence of PMNs to nylon fiber columns (Table I), although the adherence of neutrophils to nylon fiber is similar to adherence to endothelium when agents that directly alter the adhesive properties of the leukocytes are tested (29). Furthermore, thrombin did not stimulate neutrophil aggregation (Fig. 4 ), which is also a measure of neutrophil adhesive properties $(26,44)$. From these results we conclude that thrombin did not directly stimulate the adhesiveness of neutrophils under the conditions of our experiments, and that it acted primarily on the endothelial cells. This conclusion is consistent with the experiments in Fig. 3, in which incubation of endothelial monolayers with thrombin, followed by washing, resulted in enhanced neutrophil adherence. The results are also consistent with previous reports by others that thrombin does not stimulate neu- trophil functions, including aggregation and chemotaxis (7, 45-47).

The requirement for endothelial cells for the thrombin effect indicates a novel mechanism of stimulated neutrophil adherence. The observations are important because the mechanisms by which chemotactic factors and humoral inflammatory mediators promote PMN adherence to endothelium are not clearly defined. Although under some conditions chemotactic factors such as fMLP, $\mathrm{LTB}_{4}$, and C5a fragments may enhance neutrophil adherence by acting on the endothelium (48-50), each of these mediators also directly stimulates the adhesiveness of the neutrophils $(20,24,25,48,49,51)$. A recent report suggests that a direct action on the neutrophils is the dominant effect of C5a, C5a desarg, and fMLP (51). Our findings demonstrate an alternative mechanism, one that requires endothelial cells for neutrophil adherence promoted by a humoral mediator. They also suggest that under the appropriate conditions this mechanism results in neutrophil adherence that is equal in magnitude to that caused by factors that act directly on the leukocytes (Fig. 8).

The dependence of thrombin-stimulated neutrophil adherence on the presence of endothelial cells suggests that thrombin caused the EC to produce one or more factors that enhanced PMN adhesion. Our experiments support the possibility that 


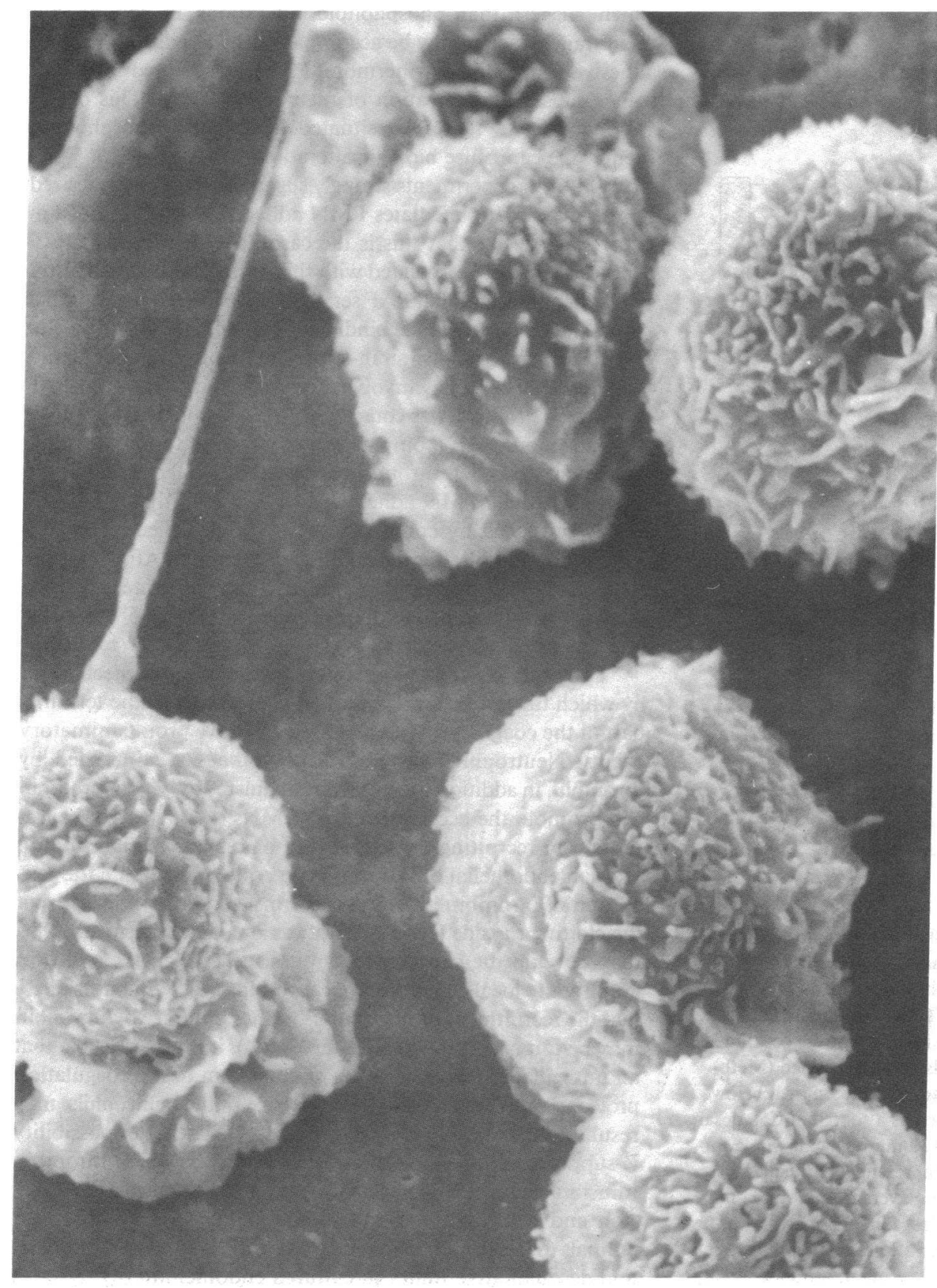

Figure 7. PAF stimulates unlabeled neutrophils to adhere to endothelial monolayers and to undergo polarization. PAF $\left(10^{-6} \mathrm{M}\right)$ was added to neutrophil suspensions overlying endothelial monolayers and the incubation was continued for $5 \mathrm{~min}$. The monolayer was then processed and examined by phase contrast and scanning electron microscopy as described in Fig. 2. A photograph of a field examined by scanning electromicrography (magnification $\times 7,920)$ is shown.
PAF synthesized by the endothelial cells may directly promote the response, perhaps by acting as an adhesive molecule or by activating the neutrophils. The evidence that PAF participates in the endothelial cell-neutrophil interaction includes: (a) thrombin stimulates the endothelial cell-dependent adherence of PMNs and also stimulates PAF synthesis by EC $(14,15) ;(b)$ the concentration curves for thrombin-stimulated neutrophil adherence and thrombin-stimulated PAF synthesis are similar (Figs. 1 and 3; Ref. 14); (c) the time courses of thrombin-stimulated neutrophil adherence (Fig. 3) and thrombin-stimulated PAF synthesis (14) are parallel, which suggests that endothelial cells become adhesive for neutrophils as PAF accumulates and is degraded (37); (d) PAF synthesized by endothelial cells remains cell-associated, even in the presence of high concentrations of albumin (37), as did the factor that mediated neutrophil adherence to the EC monolayers (Results); (e) prothrombin, Factor $\mathrm{Xa}$, and fibrinogen stimulate neither PMN adherence nor PAF synthesis (Fig. 5 and reference 15$),(f)$ exogenous PAF enhances neutrophil adherence to endothelium (Figs. 6 and 7); $(g)$ neutrophils pretreated with PAF become desensitized to subsequent stimulation with thrombin and PAF, but not to stimulation with fMLP and C5a desarg (Fig. 8), which suggests specific or selective desensitization $(26,27,52) ;(h)$ in other studies we have found evidence that leukotriene $\mathrm{C}_{4}$ promotes neutrophil adherence to endothelial monolayers by a mechanism that may also involve PAF synthesis by the EC (52a).

These observations, especially the desensitization studies, suggest that PAF synthesized by thrombin-stimulated endothelial 

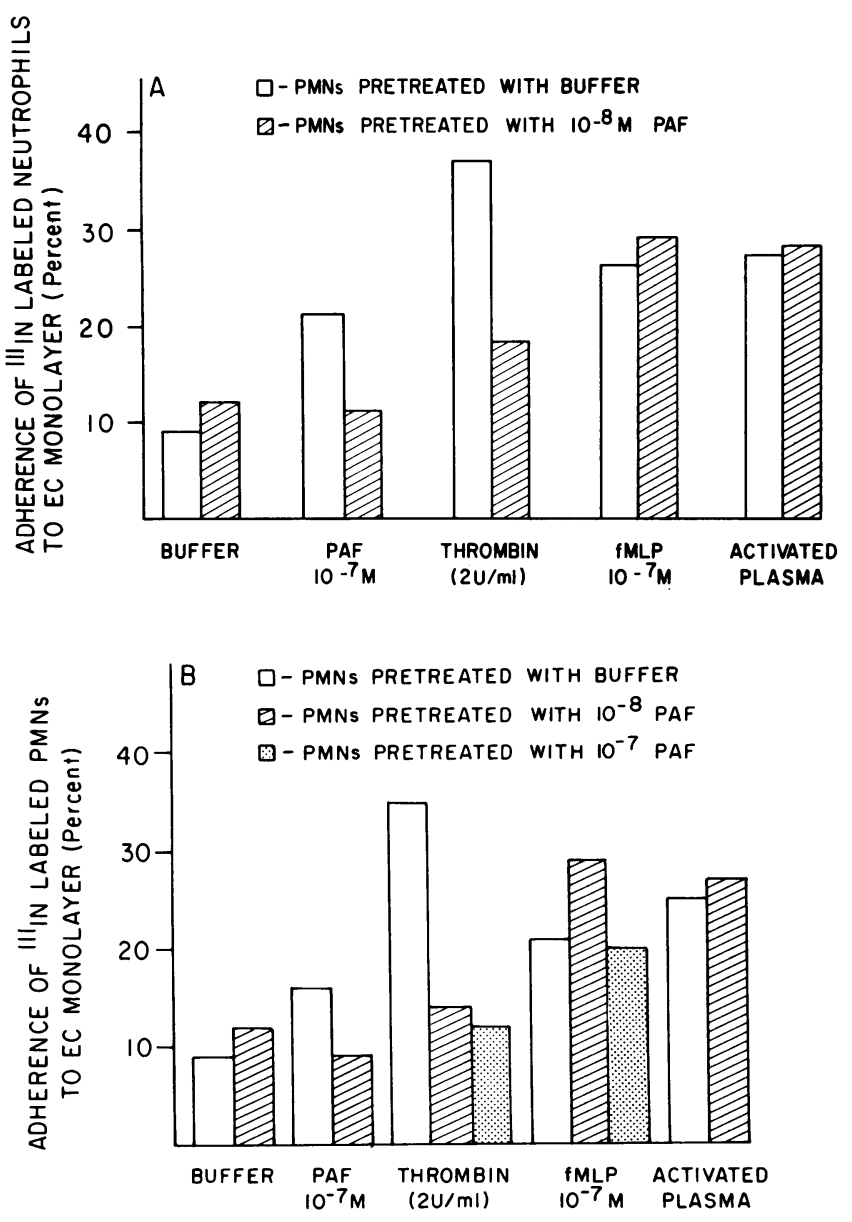

Figure 8. Pretreatment with PAF specifically inhibits neutrophil adherence to thrombin-stimulated endothelium. $(A)$ Aliquots of ${ }^{111}$ In-labeled PMN suspension were incubated with buffer (open bars) or $10^{-8}$ $\mathrm{M}$ PAF (hatched bars) for $5 \mathrm{~min}$ at $37^{\circ} \mathrm{C}$. They were then added to EC monolayers, an agonist was added, the incubation was continued for $5 \mathrm{~min}$, and adherence of the neutrophils was determined (Methods). The agonist used to stimulate PMN adherence is shown below each pair of bars. Activated plasma was used as a source of C5a desarg and was prepared by incubating zymosan $(20 \mathrm{mg} / \mathrm{ml})$ with whole human plasma as described (20). The figure represents the mean data from four experiments, each using EC monolayers from a different isolate. The standard deviation was $8 \%$ or less for each mean with the exception of the buffer-pretreated, thrombin-stimulated bar where it was $20 \%$. (B) The results of an individual experiment are shown. Neutrophils were incubated with buffer (open bars), $10^{-8} \mathrm{M}$ PAF (hatched bars), or $10^{-7} \mathrm{M}$ PAF (stippled bars) for $5 \mathrm{~min}$ at $37^{\circ} \mathrm{C}$. They were then transferred to endothelial monolayers, a second agonist was added, and adherence was determined as described in Fig. $8 \mathrm{~A}$.

cells is appropriately located, presumably in the plasma membrane, to interact with adjacent neutrophils. The molecular events that may be involved in such an adhesive interaction are unknown at this time, and it is not clear from our current understanding of the arrangement of phospholipids in cell membranes how PAF could be situated to accomplish this interaction. However, alterations in the phospholipid composition of the outer membrane of erythrocytes are associated with their enhanced adherence to human monocytes (53), and may favor the adherence of sickled erythrocytes to endothelial cells (53-55), which suggest that phospholipid alterations in the plasma membranes of cells may be accompanied by alterations in their adhesive properties. Furthermore, PAF incorporated into liposomes causes the activation of macrophages (56). This observation indicates that PAF situated in a model phospholipid membrane can cause biologic alterations in target cells.

While our experiments strongly suggest that PAF synthesized by the EC directly mediates PMN adherence, they do not unequivocally prove that this is the case. It is possible that PAF synthesis is closely associated with thrombin-stimulated neutrophil adherence, and that PAF serves as an intermediate, but that it does not directly mediate binding of the PMNs at the molecular level. Furthermore, thrombin-stimulated neutrophil adherence to endothelial cells may involve mechanisms in addition to PAF synthesis. Thrombin was consistently a more potent agonist than was exogenous PAF (compare Figs. 1 and $3 B$ to Fig. $6 \mathrm{~B}$; Fig. 8). This suggests that thrombin causes additional changes in the EC that mediate PMN adherence, or that PAF that is endogenously produced by endothelial cells is more effective in mediating neutrophil adhesion than is exogenous PAF. PAF that is endogenously produced by the EC may be protected from rapid uptake and degradation by the neutrophils $(57,58)$, because it remains cell-associated $(14,37)$.

The observations reported here indicate a new mechanism by which thrombin, a protease that is produced in the terminal part of the coagulation cascade (16), can have proinflammatory effects. Neutrophil adherence to endothelium stimulated by thrombin, in addition to indirect mechanisms by which thrombin can promote the accumulation of PMNs $(46,59)$, may be important in recruiting the leukocytes to areas of vascular injury. Human endothelial cells have the potential to facilitate the generation of thrombin by both the intrinsic and extrinsic limbs of the clotting cascade (60-62). Furthermore, adherent neutrophils may develop the capacity to synthesize tissue factor and thus amplify the local generation of thrombin (63). While it is likely that the recruitment of neutrophils to sites of injury by thrombin may be important in vascular repair (64), it is also possible that an unregulated response of the endothelium to the coagulation protease, or unregulated hyperadherence of the neutrophils, may result in thrombosis or vascular injury (1). The latter possibility is supported by experimental observations in which thrombin infusion caused PMN accumulation in the pulmonary circulation and neutrophil-dependent pulmonary vascular injury in animals $(65,66)$, and adherent, activated PMNs caused cytotoxic and desquamative injury to cultured endothelium $(67,68)$.

\section{Acknowledgments}

The authors are grateful to Dr. George Broze for the gift of thrombin and Factor Xa; Dr. Joshua Rokach for leukotriene $\mathrm{B}_{\mathbf{4}}$; Dr. John Pike for $\mathrm{PGI}_{2}$; Bill Baker and the staff of the Radiopharmacy Department, University of Utah, for the gift of "'Indium and their help in neutrophil labeling, and to Dr. Elizabeth Hammond and Jeanette Taylor for their help with electron microscopy. We thank the nurses and staff of the Labor and Delivery Unit, LDS Hospital, for their valuable help in collecting umbilical cord samples; Donelle Benson for technical assistance; Leona Archuleta for preparation of the manuscript; and Carol Evans for preparation of the figures.

This work was supported by awards from the Nora Eccles Treadwell Foundation and the Richard A. and Nora Eccles Harrison Fund for Cardiovascular Research; by grant-in-aid 84975 from the American Heart Association, with funds contributed in part by the Utah Heart 
Association, and by Public Health Service Clinic Investigator Award HL00696 from the National Heart, Lung, and Blood Institute.

\section{References}

1. Needleman, S. W., and J. C. Hoak. 1982. Platelets and leukocytes in thrombosis. In Hemostasis And Thrombosis. Basic Principles and Clinical Practice. R. W. Colman, J. Hirsch, V. J. Marder, and E. W. Salzman, editors. J. B. Lippincott, Philadelphia, PA. 716-725.

2. Dalldorf, F. G., C. N. Carney, C. E. Rackley, and R. B. Raney. 1968. Pulmonary capillary thrombosis in septicemia due to gram-positive bacteria. J. Am. Med. Assoc. 206:583-586.

3. Gruber, H. E., and M. H. Weisman. 1983. Aortic thrombosis during sigmoidoscopy in Behcet's syndrome. Arch. Intern. Med. 143: 343-345.

4. Elliott, C. G., G. A. Zimmerman, J. F. Orme, A. H. Morris, and J. D. Mortensen. 1985. Granolocyte aggregation in adult respiratory distress syndrome (ARDS): serial histologic and physiologic observations. Am. J. Med. Sci. 289:70-74.

5. Zimmerman, T. S., J. Fierer, and H. Rothberger. 1977. Blood coagulation and the inflammatory response. Semin. Hematol. 14:391405.

6. Colman, R. W. 1984. Surface-mediated defense reactions. The plasma contact activation system. J. Clin. Invest. 73:1249-1253.

7. Schapira, M., E. Despland, C. F. Scott, L. A. Boxer, and R. W. Colman. 1982. Purified human plasma kallikrein aggregates human blood neutrophils. J. Clin. Invest. 69:1199-1202.

8. Wiggins R. C., and C. G. Cochrane. 1979. Hageman factor and the contact activation system. In Chemical Messengers of the Inflammatory Process. J. C. Houck, editor. Elsevier/North Holland, Amsterdam, 179-196.

9. Kaplan, A. P., M. Silverberg, J. T. Dunn, and B. Ghebrehiwet. 1982. Interaction of the clotting, kinin-forming, complement, and fibrinolytic pathways in inflammation. Ann. NY Acad. Sci. 389:25-38.

10. Deuel, T. F., R. M. Senior, J. San Huang, and G. L. Griffin. 1982. Chemotaxis of monocytes and neutrophils to platelet-derived growth factor. J. Clin. Invest. 69:1046-1049.

11. Plow, E. F. 1982. Leukocyte elastase release during blood coagulation. A potential mechanism for activation of the alternative fibrinolytic pathway. J. Clin. Invest. 69:564-572.

12. Clark, R. A., and S. J. Klebanoff. 1979. Myeloperoxidase-mediated platelet release reaction. J. Clin. Invest. 63:177-183.

13. Lotner, G. Z., J. M. Lynch, S. J. Betz, and P. M. Henson. 1980. Human neutrophil-derived platelet activating factor. J. Immunol. 124: 676-684.

14. Prescott, S. M., G. A. Zimmerman, and T. M. McIntyre. 1984. Human endothelial cells in culture produce platelet-activating factor (1-alkyl-2-acetyl-sn-glycero-3-phosphocholine) when stimulated with thrombin. Proc. Natl. Acad. Sci. USA. 81:3534-3538.

15. Zimmerman, G. A., T. M. McIntyre, and S. M. Prescott. 1985. Production of platelet-activating factor by human vascular endothelial cells: evidence for a requirement for specific agonists and modulation by prostacyclin. Circulation. 72:718-727.

16. Jackson, C. M., and Y. Nemerson. 1980. Blood coagulation. Annu. Rev. Biochem. 49:765-811.

17. O'Flaherty, J. T., R. L. Wykle, C. H. Miller, J. C. Lewis, M. Waite, D. A. Bass, C. E. McCall, and L. R. DeChatelet. 1981. 1-O-alkylsn-glyceryl-3-phosphorylcholines. A novel class of neutrophil stimulants. Am. J. Pathol. 103:70-79.

18. McManus, L. M., D. J. Hanahan, and R. N. Pinckard. 1981. Human platelet stimulation by acetyl glyceryl ether phosphorylcholine. J. Clin. Invest. 67:903-906.

19. Zimmerman, G. A., G. A. Wiseman, and H. R. Hill. 1985. Human endothelial cells modulate granulocyte adherence and chemotaxis. $J$. Immunol. 134:1866-1874.

20. Zimmerman, G. A., A. D. Renzetti, and H. R. Hill. 1984. Gran- ulocyte adherence in pulmonary and systemic arterial blood samples from patients with adult respiratory distress syndrome. Am. Rev. Respir. Dis. 129:798-804.

21. Thakur, M. L., L. J. Walsh, B. L. Zaret, and A. Gottschalk. 1982. Effect of antiarrhythmic drugs on In ${ }^{111}$-labeled leukocytes: chemotaxis and adherence to nylon wool. J. Nucl. Med. 23:131-135.

22. Peters, A. M., S. H. Saverymuttu, H. J. Reavy, H. J. Danpure, S. Osman, and J. P. Lavender. 1983. Imaging of inflammation with Indium $^{111}$ Tropolonate labeled leukocytes. J. Nucl. Med. 24:39-44.

23. MacGregor, R. R., P. Spagnuolo, and A. L. Lentnek. 1974. Inhibition of granulocyte adherence by ethanol, prednisone, and aspirin, measured with an assay system. $N$. Engl. J. Med. 291:642-646.

24. Smith, C. W., J. C. Hollers, R. A. Patrick, and C. Hassett. 1979. Motility and adhesiveness in human neutrophils. Effects of chemotactic factors. J. Clin. Invest. 63:221-229.

25. Palmblad, J., C. L. Malmsten, A. M. Udén, O. Rådmark, L. Engstedt, and B. Samuelsson. 1981. Leukotriene $B_{4}$ is a potent and stereospecific stimulator of neutrophil chemotaxis and adherence. Blood. $58: 658-661$.

26. O'Flaherty, J. T., D. L. Kreutzer, H. J. Showell, G. Vitkauskas, E. L. Becker, and P. A. Ward. 1979. Selective neutrophil desensitization to chemotactic factors. J. Cell Biol. 80:564-572.

27. O'Flaherty, J. T., C. J. Lees, C. H. Miller, C. E. McCall, J. C. Lewis, S. H. Love, and R. L. Wykle. 1981. Selective desensitization of neutrophils: further studies with 1-O-alkyl-sn-glycero-3-phosphocholine analogues. J. Immunol. 127:731-737.

28. Aubrey, B. J., J. C. Hoak, and W. G. Owen. 1979. Binding of human thrombin to cultured human endothelial cells. J. Biol. Chem. 254:4092-4095.

29. MacGregor, R. R., E. J. Macarak, and N. A. Kefalides. 1978. Comparative adherence of granulocytes to endothelial monolayers and nylon fiber. J. Clin. Invest. 61:697-702.

30. Prescott, S. M., G. A. Zimmerman, and A. R. Seeger. 1984. Leukotriene $B_{4}$ is an incomplete agonist for the activation of human neutrophils. Biochem. Biophys. Res. Commun. 122:535-541.

31. McManus, L. M., D. J. Hanahan, C. A. Demopoulos, and R. N. Pinckard. 1980. Pathobiology of the intravenous infusion of acetyl glyceryl ether phosphorylcholine (AGEPC), a synthetic platelet-activating factor (PAF), in the rabbit. J. Immunol. 124:2919-2924.

32. McManus, L. M., R. N. Pinckard, F. A. Fitzpatrick, R. A. O'Rourke, M. H. Crawford, and D. J. Hanahan. 1981. Acetyl glyceryl ether phosphorylcholine. Intravascular alterations following intravenous infusion into the baboon. Lab Invest. 45:303-307.

33. Lollar, P., and W. G. Owen. 1980. Evidence that the effects of thrombin on arachidonate metabolism in cultured human endothelial cells are not mediated by a high affinity receptor. J. Biol. Chem. 255: 8031-8034.

34. Weksler, B. B., C. W. Ley, and E. A. Jaffe. 1978. Stimulation of endothelial cell prostacyclin production by thrombin, trypsin, and ionophore A23187. J. Clin. Invest. 62:923-930.

35. Baenziger, N. L., F. J. Fogerty, L. F. Mertz, and L. F. Chernuta. 1981. Regulation of histamine-mediated prostacyclin synthesis in cultured human vascular endothelial cells. Cell. 24:915-923.

36. Glassberg, M. K., M. M. Bern, S. R. Coughlin, C. C. Haudenschild, L. W. Hoyer, H. N. Antoniades, and B. R. Zetter. 1982. Cultured endothelial cells derived from the human iliac arteries. In Vitro. 18:859866.

37. McIntyre, T. M., G. A. Zimmerman, K. Satoh, and S. M. Prescott. 1985. Cultured endothelial cells synthesize both platelet-activating factor and prostacyclin in response to histamine, bradykinin, and adenosine triphosphate. J. Clin. Invest. 76:271-280.

38. Gospodarowicz, D., K. D. Brown, C. R. Birdwell, and B. R. Zetter. 1978. Control of proliferation of human vascular endothelial cells. Characterization of the response of human umbilical vein endothelial cells to fibroblast growth factor, epidermal growth factor, and thrombin. J. Cell Biol. 77:774-788.

39. Laposata, M., D. Dovnarsky, and H. S. Shin. 1983. Thrombin- 
induced gap formation in confluent endothelial cell monolayers in vitro. Blood. 62:549-556.

40. Owen, W. G., and C. T. Esmon. 1981. Functional properties of an endothelial cell cofactor for thrombin-catalyzed activation of protein C. J. Biol. Chem. 256:5532-5535.

41. Czervionke, R. L., J. C. Hoak, and G. L. Fry. 1978. Effect of aspirin on thrombin-induced adherence of platelets to cultured cells from the blood vessel wall. J. Clin. Invest. 62:847-856.

42. Chen, S., S. Barmatoski, and M. I. Barnhart. 1979. Effect of thrombin on platelet-vessel wall interactions. Scanning Electron Microsc. III:783-789.

43. Shuman, M. A., and P. W. Majerus. 1976. The measurement of thrombin in clotting blood by radioimmunoassay. J. Clin. Invest. 58: 1249-1258.

44. Hoffstein, S. T., R. S. Friedman, and G. Weissmann. 1982. Degranulation, membrane addition, and shape change during chemotactic factor-induced aggregation of human neutrophils. J. Cell Biol. 95:234241.

45. O'Flaherty, J. T., H. J. Showell, E. L. Becker, and P. A. Ward. 1979. Neutrophil aggregation and degranulation. Effect of arachidonic acid. Am. J. Pathol. 95:433-444.

46. Kay, A. B., D. S. Pepper, and M. R. Ewart. 1973. Generation of chemotactic activity for leukocytes by the action of thrombin on human fibrinogen. Nature New Biology. 243:56-57.

47. Bar-Shavit, R., A. Kahn, J. W. Fenton, II, and G. D. Wilner. 1983. Chemotactic response of monocytes to thrombin. J. Cell. Biol. 96:282-285.

48. Hoover, R. L., R. T. Briggs, and M. J. Karnovsky. 1978. The adhesive interaction between polymorphonuclear leukocytes and endothelial cells in vitro. Cell. 14:423-428.

49. Zimmerman, G. A., and H. R. Hill. 1984. Inflammatory mediators stimulate granulocyte adherence to cultured human endothelial cells. Thromb. Res. 35:203-217.

50. Hoover, R. L., M. J. Karnovsky, K. F. Austen, E. J. Corey, and R. A. Lewis. 1984. Leukotriene $B_{4}$ action on endothelium mediates augmented neutrophil/endothelial adhesion. Proc. Natl. Acad. Sci. USA. 81 : 2191-2193.

51. Tonnesen, M. G., L. A. Smedly, and P. M. Henson. 1984. Neutrophil-endothelial cell interactions. Modulation of neutrophil adhesiveness induced by complement fragments C5a and C5a desarg and formyl-methionyl-leucyl-phenylalanine in vitro. J. Clin. Invest. 74:15811592.

52. Shaw, J. O., R. N. Pinckard, K. S. Ferrigni, L. M. McManus, and D. J. Hanahan. 1981. Activation of human neutrophils with 1-Ohexadecyl/octodecyl-2-acetyl-sn-glyceryl-3-phosphorylcholine (plateletactivating factor). J. Immunol. 127:1250-1255.

52a. Zimmerman, G. A., T. M. McIntyre, and S. M. Prescott. 1985. Thrombin and leukotriene $\mathrm{C}_{4}$ stimulate the adherence of human neutrophils by an endothelial cell-dependent mechanism. Clin. Res. 33:358a. (Abstr.).

53. Schwartz, R. S., Y. Tanaka, I. J. Fidler, D. T.-Y. Chiu, B. Lubin, and A. J. Schroit. 1985. Increased adherence of sickled and phosphatidylserine-enriched human erythrocytes to cultured human peripheral blood monocytes. J. Clin. Invest. 75:1965-1972.

54. Hoover, R. L., R. Rubin, G. Wise, and R. Warren. 1979. Adhesion of normal and sickle erythrocytes to endothelial monolayer cultures. Blood. 54:872-876.

55. Hebbel, R. P., O. Yamada, C. F. Moldow, H. S. Jacob, J. G. White, and J. W. Eaton. 1980. Abnormal adherence of sickle erythrocytes to cultured vascular endothelium: possible mechanism for microvascular occlusion in sickle cell disease. J. Clin. Invest. 65:154-160.

56. Hayashi, H., I. Kudo, K. Inoue, H. Nomura, and S. Nojima. 1985. Macrophage activation by PAF incorporated into dipalmitoylphosphatidylcholine-cholesterol liposomes. J. Biochem. 97:1255-1258.

57. Lee, T., B. Malone, S. I. Wasserman, V. Fitzgerald, and F. Snyder. 1982. Activities of enzymes that metabolize platelet-activating factor (1-alkyl-2-acetyl-sn-glycero-3-phosphocholine) in neutrophils and eosinophils from humans and the effect of a calcium ionophore. Biochem. Biophys. Res. Commun. 105:1303-1308.

58. Chilton, F. H., J. T. O'Flaherty, J. M. Ellis, C. L. Swendsen, and R. L. Wykle. 1983. Metabolic fate of platelet-activating factor in neutrophils. J. Biol. Chem. 258:6357-6361.

59. Hugli, T. E. 1977. Complement factors and inflammation: effects of $\alpha$-thrombin on components $C_{3}$ and $C_{5}$. In Chemistry And Biology of Thrombin. R. L. Lundblad, J. W. Fenton, and K. G. Mann, editors. Ann Arbor Science Publishers, Inc, Ann Arbor, MI 345-360.

60. Rodgers, G. M., and M. A. Shuman. 1983. Prothrombin is activated on vascular endothelial cells by factors $\mathrm{Xa}$ and calcium. Proc. Natl. Acad. Sci. USA. 80:7001-7005.

61. Stern, D. M., M. Drillings, H. L. Nossel, A. Hurlet-Jensen, K. S. LaGamma, and J. Owen. 1983. Binding of factor IX and IXa to cultured vascular endothelial cells. Proc. Natl. Acad. Sci. USA. 80:41194123.

62. Colucci, M., G. Balconi, R. Lorenzet, A. Pietra, D. Locati, M. B. Donati, and N. Semeraro. 1983. Cultured human endothelial cells generate tissue factor in response to endotoxin. J. Clin. Invest. 71:18931896.

63. Lerner, R. G., R. Goldstein, and J. C. Nelson. 1977. Production of thromboplastin (tissue factor) and thrombi by polymorphonuclear neutrophilic leukocytes adhering to vein walls. Thromb. Res. 11:11-22.

64. Deuel, T. F., and J. San Huang. 1984. Platelet-derived growth factor. Structure, function, and roles in normal and transformed cells. J. Clin. Invest. 74:669-676.

65. Cooper, J. A., S. J. Solano, R. Bizios, J. E. Kaplan, and A. B. Malik. 1984. Pulmonary neutrophil kinetics after thrombin-induced intravascular coagulation. J. Appl. Physiol. Respir. Environ. Exercise Physiol. 57(3):826-832.

66. Tahamont, M. V., and A. B. Malik. 1983. Granulocytes mediate the increase in pulmonary vascular permeability after thrombin embolism. J. Appl. Physiol. Respir. Environ. Exercise Physiol. 54(6):14891495.

67. Sacks, T., C. F. Moldow, P. R. Craddock, T. K. Bowers, and H. S. Jacob. 1978. Oxygen radicals mediate endothelial cell damage by complement-stimulated granulocytes. An in vitro model of immune vascular damage. J. Clin. Invest. 61:1161-1167.

68. Harlan, J. M., B. R. Schwartz, M. A. Reidy, S. M. Schwartz, H. D. Ochs, and L. A. Harker. 1985. Activated neutrophils disrupt endothelial monolayer integrity by an oxygen radical-independent mechanism. Lab Invest. 52:141-150. 